\title{
HEU Transparency Implementation Program and its Radiation Safety Program
}

\author{
R. Radev
}

January 31, 2002

Lawrence

Livermore

National

Laboratory 


\section{DISCLAIMER}

This document was prepared as an account of work sponsored by an agency of the United States Government. Neither the United States Government nor the University of California nor any of their employees, makes any warranty, express or implied, or assumes any legal liability or responsibility for the accuracy, completeness, or usefulness of any information, apparatus, product, or process disclosed, or represents that its use would not infringe privately owned rights. Reference herein to any specific commercial product, process, or service by trade name, trademark, manufacturer, or otherwise, does not necessarily constitute or imply its endorsement, recommendation, or favoring by the United States Government or the University of California. The views and opinions of authors expressed herein do not necessarily state or reflect those of the United States Government or the University of California, and shall not be used for advertising or product endorsement purposes.

This work was performed under the auspices of the U.S. Department of Energy by the University of California, Lawrence Livermore National Laboratory under Contract No. W-7405-Eng-48.

This report has been reproduced directly from the best available copy.

Available electronically at http://www.doe.gov/bridge

Available for a processing fee to U.S. Department of Energy and its contractors in paper from

U.S. Department of Energy

Office of Scientific and Technical Information

P.O. Box 62

Oak Ridge, TN 37831-0062

Telephone: (865) 576-8401

Facsimile: (865) 576-5728

E-mail: reports@adonis.osti.gov

Available for the sale to the public from

U.S. Department of Commerce

National Technical Information Service

5285 Port Royal Road

Springfield, VA 22161

Telephone: (800) 553-6847

Facsimile: (703) 605-6900

E-mail: orders@ntis.fedworld.gov

Online ordering: http://www.ntis.gov/ordering.htm

OR

Lawrence Livermore National Laboratory

Technical Information Department's Digital Library

http://www.llnl.gov/tid/Library.html 


\title{
HEU Transparency Implementation Program and its Radiation Safety Program
}

\author{
Radoslav Radev \\ Lawrence Livermore National Laboratory
}

\section{Background}

In February 1993, the Governments of the United States (U.S.) and the Russian

Federation (R.F.) signed a bilateral Agreement for the U.S. purchase of low enriched uranium (LEU) derived from 500 metric tons (MT) of highly enriched uranium (HEU) resulting from the dismantlement of Russian nuclear weapons.. The HEU Purchase Agreement serves important national security and nonproliferation policy imperatives for both countries since its implementation reduces the quantity of surplus Russian HEU that could be stolen and diverted for weapons use. In return, Russia receives much needed U.S. dollars over a 20-year delivery period. In 2001, Russia received over half a billion US dollars from the purchase of the LEU blended from 30 MT HEU.

As part of this Agreement, transparency rights were agreed upon that provide confidence to both governments that the nonproliferation objectives of the Agreement are being fulfilled. While the U.S. Department of State, in concert with the U.S. Department of Energy's (DOE) National Nuclear Security Administration (NNSA) is responsible for negotiating transparency rights associated with this nuclear material, the NNSA is responsible for implementing those rights. These rights allow U.S. and.R.F. personnel (called "monitors") to visit the processing facilities and observe the steps for processing the HEU into fuel for nuclear reactors. In this fashion, the processing of HEU to LEU is made "transparent."

For DOE, there are three transparency objectives:

- that the HEU is extracted from nuclear weapons

- that this same HEU is oxidized, and

- that the HEU is blended into LEU

For MINATOM, the transparency objective is:

- that the LEU is fabricated into fuel for commercial nuclear power reactors.

The transparency is based on visits by designated transparency monitors (100 preapproved U.S. and Russian monitors) with specific rights to monitor and to access storage and processing areas to provide confidence that the nonproliferation goals of the agreement are met.

The Highly Enriched Uranium (HEU) Transparency Implementation Program (TIP), within NNSA implements the transparency provisions of the bilateral agreement. It is constantly making progress towards meeting its objectives and gathering the information necessary to confirm that Russian weapons-usable HEU is being blended into LEU. Since the first shipment in 1995 through December 2001, a total of 141 MT of weaponsgrade HEU, about $28 \%$ of the agreed total and equivalent to 5,650 nuclear weapons, was converted to LEU, further reducing the threat of this material returning back into nuclear 
weapons. In the year 2001, the LEU sold to electric utility customers for fuel was sufficient to supply the annual fuel needs for about 50 percent of the U.S. installed nuclear electrical power generation capacity.

There are four primary uranium processing activities involved in converting HEU metal components extracted from dismantled nuclear weapons into fuel for power reactors:

- Converting HEU metal to purified HEU oxide

- Converting purified HEU oxide to HEU hexafluoride

- Downblending HEU hexafluoride to LEU hexafluoride

- Converting LEU hexafluoride into reactor fuel

The first three processes are currently being performed at four Russian nuclear processing facilities: Mayak Production Association (MPA), Electrochemical Plant (ECP), Siberian Chemical Enterprise (SChE), and Ural Electrochemical Integrated Plant (UEIP). Following the blending down of HEU, the LEU hexafluoride is loaded into industry standard 30B cylinders at the downblending facilities and transported to St. Petersburg, Russia. From there the LEU is shipped by sea to the United States where it is converted into fuel to be used in nuclear power plants. There are six U.S. facilities processing LEU subject to the HEU purchase agreement: the Portsmouth uranium enrichment plant, Global Nuclear Fuel - America, Framatome-Lynchburg, Framatome-Richland, Westinghouse-Hematite, and Westinghouse Fuel Fabrication Facility.

\section{Transparency Monitoring}

HEU-TIP experts monitor the four Russian facilities through a Transparency Monitoring Office (TMO) at UEIP and series of Special Monitoring Visits (SMV). The HEU-TIP conducts up to 24 SMV trips annually to all four Russian facilities where monitoring teams observe and record information on Russian HEU processing. Monitor activities include observing HEU process operations, an inventory of in-process containers, and conducting nondestructive assay (NDA) measurements on HEU containers to determine

${ }^{235} \mathrm{U}$ enrichment. The TMO monitors have daily access to the UEIP facility and support SMV teams at the other sites.

The HEU-TIP employs U.S. built portable NDA equipment in R.F. processing facilities to determine the ${ }^{235} \mathrm{U}$ enrichment of HEU. In addition, the U.S. designed and built Blend Down Monitoring System (BDMS) measures the enrichments and flow rates of HEU hexafluoride gas and traces the HEU through the blending "tee" into the LEU produced.

\section{BDMS Equipment}

Measurement of the enrichment, flow rate and the tracing of HEU to LEU: is a key element in determining that the Russian weapons-usable HEU is being blended into LEU. The BDMS equipment installed at the UEIP in 1999 was designed to continuously monitor and record these measurements. The BDMS equipment consists of six 
monitoring units installed on two blending tees where HEU is diluted to LEU. The BDMS equipment incorporates six ${ }^{57} \mathrm{Co}$ sources of $110 \mu \mathrm{Ci}$ activity each and $24{ }^{252} \mathrm{Cf}$ sources of $2 \mathrm{mCi}$ each. A second BDMS is to be installed at ECP in 2002 and negotiations for the installation of a BDMS at $\mathrm{SChE}$ are underway.

\section{Data Analyses}

HEU-TIP maintains a central Data Archive Retrieval and Transfer System (DARTS) that is linked from LLNL to 10 DOE sites with about 100 registered users in the United States. DARTS provides a secure data link to transparency data obtained in Russia that includes material processing information obtained as a result of monitoring activities. U.S. technical analysts access this data to generate technical assessment and processing reports.

\section{Humanitarian Efforts in Russian Communities}

The HEU-TIP supports humanitarian activities within the Nuclear Cities where the visited Russian facilities are located. Many of the HEU monitors share their off-hours with Russian children from local schools and orphanages. Many HEU monitors contributed personal funds and time to purchase and distribute Christmas gifts, candy bags, toys, clothes, televisions sets, VCRs and tapes to children hospitals and orphanages.

\section{HEU-TIP Health and Safety Program}

Living and working in Russia presents a moderately greater risk to workers than they are exposed to in the United States. There is a need to monitor U.S. government, national laboratory and contractor employees while working in Russia. Lawrence Livermore National Laboratory (LLNL) provides all the Health and Safety (H\&S) related needs for the HEU-TIP: assessment of the health and safety risks and hazards, personnel radiation safety, both DOE and Russian regulatory safety compliance, special issues associated with BDMS, and medical support. A comprehensive H\&S Plan has been developed and implemented for the safe conduct of HEU-TIP activities in Russia.

The main components of the HEU-TIP radiation safety program are the H\&S Plan, the external and internal dosimetry and dose information management. The monitoring of the external dose is provided through dosimeter badges supplied by LLNL to each monitoring team before the trip: Each of the dosimeter badges includes a TLD, nuclear accident dosimeter (NAD) and CR-39 neutron dosimeter. TLD provides the shallow, deep and neutron doses. NAD and CR-39 are processed only in case of nuclear accident. The Russian host facility provides to each U.S. monitor one Russian TLD dosimeter, which measures only the deep dose. Every monitor caries two LLNL dosimeter badges, one of which is left in Russia as an arbitration dosimeter. The arbitration dosimeter is retrieved from Russia by the next HEU-TIP monitors after they provide the Russian hosts with the dose from the previous visit. The arbitration dosimeter is read only if there is discrepancy between the Russian and U.S. determined doses. Last year LLNL supplied about 900 dosimeter badges including the arbitration and control dosimeters and about 60 spare dosimeters for the Transparency Monitoring Office. 
Internal dose from potential intake of $\mathrm{U}$ or Plutonium $(\mathrm{Pu})$ is evaluated by urine sample bioassays. Baseline bioassays for $\mathrm{U}$ and $\mathrm{Pu}$ are performed for every active monitor. Post trip bioassays for $\mathrm{U}$ are performed for every monitor after each trip using state-of-the-art inductively coupled plasma mass spectrometry (ICP-MS) technique. Post-trip bioassays for $\mathrm{Pu}$ are performed only on an as needed basis.

Following each trip a written external dose report is provided to HEU-TIP and to the respective Russian host facility. Internal dose reports are provided to HEU-TIP for each calendar quarter. Annual dose report including all radiation safety issues is provided to HEU-TIP for each calendar year. An individual annual dose report of the total dose is provided to each monitor and to his or her home organization. Any affected monitor is provided with a health physics investigation summary of any abnormal external or internal dose. All dosimetry and health and safety information is maintained in a specially designed Health Physics (HP) database. This is a relational database linked to the monitor and trip databases. The HP database assists the Health Physicist and H\&S Coordinator in planning and recording all TLD assignments, distribution, returns and arbitration TLD information, assessing external dose, delivery and receipt of the bioassay kits and the assessment of the internal doses and compliance tasks on internal and external dosimetry.

BDMS operation in the Russian plant presents specific problems: it has a total of $30{ }^{57} \mathrm{Co}$ and ${ }^{252} \mathrm{Cf}$ sources distributed in various BDMS components all in one room. From the operational point of view it is desirable to have stronger sources; however, the strength of the sources must comply with the Russian radiation safety regulatory limits at the surface and at one meter away from any radiation-producing device. Due to their radioactive decay, the ${ }^{57} \mathrm{Co}$ sources are replaced each year and the ${ }^{252} \mathrm{Cf}$ sources are replaced every two years. LLNL provided support in the shielding design, completed Monte Carlo calculations of the neutron and gamma spectra and dose rates around BDMS, assisted the Russian counterparts in calibration issues of their rem ball, participated in the dose rate measurements and jointly evaluated the results and developed a joint radiation safety report. LLNL also discussed with the Russian specialists the path for reducing the evaluated dose rates due to rem ball calibration with other than ${ }^{252} \mathrm{Cf}$ neutron sources, as well as due to neutron moderation in the BDMS moderator and shielding.

LLNL also assists the Russian radiation safety specialists in personnel neutron dosimetry by providing bubble dosimeters, automatic readers, and training expertise. The bubble dosimeters have unsurpassed neutron sensitivity and are completely insensitive towards gamma and X-rays. On the other hand the manufacturer's warranty of their optimal performance is only 90 days, which puts severe constrains for their use in the HEU transparency program. In addition to the shipping and customs delays, the Russians require a 30-day inspection period for any device or item brought into their nuclear facilities before it can be released for use. LLNL initiated experimental study of the lifespan of the bubble dosimeters in order to extend the usefulness of the supplied bubble dosimeters. The results of this work indicated that under certain conditions of use and storage of the bubble dosimeters, their life-span is at least six months. Based on this study, the bubble dosimeter's manufacturer issued a written statement, confirming the 
extended life of the bubble dosimeters. The LLNL work increased significantly the cost effectiveness of the bubble dosimeters use in the HEU-TIP. Currently LLNL is in . process of certifying the bubble dosimeters for use not only in the four nuclear facilities, but also for use at other nuclear facilities in the Russian Federation.

The radiation safety issues and accomplishments of the HEU-TIP were presented in 2001 at the Health Physics Society (HPS) annual meeting in Cleveland, $\mathrm{OH}$, and at the Radiation Safety conference in St. Petersburg, Russia.

The medical support for HEU-TIP includes: a health risk assessment of working in Russia and developing support program, establishing and maintaining a medical supply system at TMO, supporting the U.S. teams with medical kits, managing medical emergency evacuation contract, and evaluating and remediating emerging health risks for the HEU-TIP workers while in Russia.

The past eight years of HEU-TIP activities in Russia have confirmed that all the work has been conducted in a safe manner. This is important message not only for the HEU monitors, but also for the entire HEU-TIP staff, DOE and the general public.

\section{Achievements and Future Path}

Both U.S. and R.F. monitors, and their respective managers are to be commended for their hard work and support given to the HEU-TIP. Together our countries have about 190 active monitors available to support the Program efforts in addition to their working full time jobs. Our monitors work diligently to inventory in-process containers, observe operations, perform NDA testing, and examine MC\&A documents. The personal: interactions between the U.S. and R.F. technical experts are exemplary and have proven to be an important aspect of the transparency regime.

With almost eight years of experience in developing transparency measures, the HEUTIP has attained a unique leadership role. Since 1993 the Program has exceeded 1,000 monitor-weeks at the R.F. uranium processing plants. With the experience and expertise derived from this accomplishment, HEU-TIP provides leadership to other U.S.

Government programs involved in transparency measures and their interaction with R.F. nuclear material processing facilities. HEU-TIP continues to provide support and coordination to these programs through such activities as inter-program discussions, as well as H\&S plans and support. Based upon the accumulated experience, LLNL is providing specialized radiation safety support to the DOE monitors traveling to Russia under the Plutonium Disposition Program and is negotiating radiation safety support to the DOE Material Protection, Control and Accountability (MPC\&A) monitors in Russia.

Future HEU-TIP efforts in the Russian Federation are aimed towards strengthening transparency measures in a cost-effective, nonintrusive manner. In doing so, the Program expects to provide additional information to assure that the HEU blended into LEU originated from weapons components. 